\title{
Micromonospora purpureochromogenes (Waksman and Curtis 1916) comb. nov. (Subjective Synonym: Micromonospora fusca Jensen 1932)
}

\author{
GEORGE M. LUEDEMANN
}

Microbiology Division, Schering Corporation, Bloomfield, New Jersey 07003

\begin{abstract}
A search for a suitable strain to serve as the neotype for Micromonospora fusca Jensen 1932 has uncovered a number of Micromonospora strains which produce a dark-brown, agar-diffusible pigment and which are physiologically and morphologically similar to $M$. fusca. One of the strains resembling $M$. fusca is IMRU 3343 (= ATCC 27007), the type strain of Streptomyces purpureochromogenes (Waksman and Curtis 1916) Waksman and Henrici, 1948. [The strain of Streptomyces purpureochromogenus (sic) held at the Centraalbureau voor Schimmelcultures, Baarn, Netherlands, and S. purpureochromogenes ATCC 3343 have been identified as belonging to $S$. griseus, and they bear no relationship to IMRU 3343 or to the original description of Actinomyces purpeo-chromogenus (sic) Waksman and Curtis 1916.] It has been determined that the type strain (IMRU 3343) of $S$. purpureochromogenes is a micromonospora, and therefore this organism is transferred to the genus Micromonospora $\emptyset$ rskov as $M$. purpureochromogenes (Waksman and Curtis) comb. nov. Because the species $M$. purpureochromogenes and $M$. fusca are so similar, their names are here regarded as subjective synonyms. The specific epithet purpureochromogenes has priority over fusca, and the correct name of this organism is therefore $M$. purpureochromogenes.
\end{abstract}

Jensen (4) characterized Micromonospora fusca as producing a dark-brown to black, diffusible pigment which he believed differed from the pigments produced by the chromogenic streptomycetes. Of 67 micromonosporae Jensen isolated from Australian soils, only two strains were found which produced such a dark, diffusible pigment. From personal observations, few micromonosporae from soil produce a dark-brown, diffusible pigment which diffuses throughout the medium in a petri dish. On the other hand, a dark-brown to black, agardiffusible pigment is produced by many streptomycetes.

A search for a potential neotype strain for Micromonospora fusca uncovered a small number of soil isolates which produced an abundant, dark-brownish-black, diffusible pigment and which appeared to be related with respect to a number of other characteristics (see reference 11, p. $105,109,110$ for a discussion of Micromonospora stains identified as $M$. fusca). While the selection of a neotype from these isolates was being considered, two additional chromogenic micromonosporae were received and were found to agree in almost all respects with the members of the chromogenic group under study. One of these strains, M-1021, was received from Louise Potter of Elmira College. It had been isolated from a mud sample from Flathead Lake, Montana, and had been identified as Micromonospora fusca by Lien-hwa T'ao (M.S. thesis, Vassar College, Poughkeepsie, N.Y., 1958). The other strain was received from Ruth E. Gordon of the Institute of Microbiology, Rutgers University (IMRU), as Streptomyces purpureochromogenes IMRU 3343.

T. G. Pridham of the Northern Regional Research Laboratory, Peoria, Ill., informed me that the strain of Streptomyces purpureochromogenes held at the Centraalbureau voor Schimmelcultures, Baarn, Netherlands (CBS), and that the strain of this organism held at the American Type Culture Collection, Rockville, Md. (ATCC 3343), were streptomycetes, whereas IMRU 3343 appeared to be a strain of Micromonospora. Ettlinger et al. (2) had pointed out that the CBS and ATCC stains of 
Streptomyces purpureochromogenes belonged to $S$. griseus. In 1964 and 1965, Pridham regarded $S$. purpureochromogenes IMRU 3343 as belonging to a subspecies of $S$. griseus. However, in 1969 (16) he placed $S$. purpureochromogenes IMRU 3343 in a group of nontypical streptomycetes based upon a whole-cell hydrolysate yielding meso or D-diaminopimelic acid, or both; IMRU 3343 was also noted to contain a trace of L-diaminopimelic acid, which would indicate its affinity with other micromonosporae.

Although Jensen gave the name Micromonospora fusca in his 1932 publication and cited two strains as typifying this species (strains 125 II and $279 \mathrm{Sb}$ ), the description of strain 125 II in his paper of 1930 is quoted below because it is more detailed and more closely approximates the 1916 description of Waksman and Curtis for Actinomyces purpeo-chromogenus (sic).

\section{Strain 125 II (Jensen 1930; Micromonospora fusca Jensen 1932).}

"Hyphae 0.3-0.4 $\mu$ thick. Spores spherical to slightly oval, 1.0-1.2 $\mu$. Dextrose-asparagin-agar. Fair growth after 8 days. Vegetative mycelium raised, granulated, red-brown with moist, darkbrown spots. After 14 days the mycelium is mahogany-brown with nearly black, moist granules of spores on surface. A light coffee-brown soluble pigment is formed. After 24-30 days the growth is nearly all black, pigment deeper brown.

Starch-casein-agar: Scant growth after 8 days. Vegetative mycelium flat, developing into medium, red-brown, after 14 days turning nearly black; light-brown soluble pigment. After 21 days growth is all black, surface dry, with metallic lustre; pigment deep-brown. Very slight diastatic activity on plate culture.

Gelatin, 25 days $22-24^{\circ} \mathrm{C}$, stab culture: Small granules in stab, first orange, later turning brown. Slow, saccate liquefaction. No pigment in gelatin.

Potato: Scant growth after 14 days. Vegetative mycelium raised, granulated, orange with red-brown spots. After 21-30 days a brownish soluble pigment diffuses through the plug; growth unchanged.

Milk: Very slow growth. After 60 days small greyish-brown granules on side of tube, faint greyish-brown discoloration of milk, but no coagulation or clearing.

Saccharose-nitrate-solution: Scant growth after 9 days. Numerous small loose greyish flakes on bottom of tube. Saccharose is in- verted (strong reduction of Fehling's solution). Nitrate is reduced to nitrite. No acidity."

The Waksman and Curtis (23) description of Actinomyces purpeo-chromogenus (sic) is of interest because it notes that something was different about this organism which did not produce an earthy odor, aerial mycelium, or typical conidia but produced spherical, nonstaining bodies, 0.75 to $1.0 \mu \mathrm{m}$ in diameter.

\section{"Act. purpeo-chromogenus, n. sp." (Waksman and Curtis 1916).}

"Czapeck's Agar. Colonies small, 0.5 to 1.5 $\mathrm{mm}$. in diameter, developing very slowly. They are brown in color with a brown to black reverse. Surface of colony is glossy, and raised in the centre. A brown soluble pigment is produced, which shows a distinct purple tinge, when viewed by transmitted light. Aerial mycelium is formed later. When culture is over 4 weeks old a brownish purple to black surface mycelium is formed. Margin of colony is waxy-yellow in color and lichnoid in appearance. No odor could be detected. Microscopically, no difference could be seen between the substratum and surface mycelium, a condition which suggested the question whether or not the latter could be called aerial mycelium. No conidia could be found. Substratum mycelium seems to break up into spherical non-staining bodies, .75 to $1 . \mu$ in diameter (oidia?).

Gelatin. Growth very slow. Liquefaction of the gelatin is slow with the production of a brownish pigment only at a late period.

Potato plug. No growth on potato in 2 to 3 days at $30^{\circ} \mathrm{C}$. Only after 10 days the colonies were found to be very small, orange colored, grouping in a bead-like fashion. Colonies become dark brown with age. Potato slightly colored brown.

Czapeck's solution. Flaky growth on the bottom of the flask.

Hab. Isolated once from the California adobe soil. Herbarium No. 49."

A similar but expanded description of this species was given by Waksman (reference $20, p$. 142-143). IMRU 3343 was subsequently designated by Waksman (22) as the type stain.

According to Krasil'nikov $(7,8)$, Actinomyces purpureochromogenes Waksman and Curtis 1916 was believed to be a variant (subspecies?) of Actinomyces melanocyclus Krainsky 1914, synonym Actinomyces melanosporeus Krainsky 1914; also see Pridham et al. (17). Baldacci and Locci (1) mention that 
Actinomyces melanosporeus Krainsky 1914 and Actinomyces melanocyclus Krainsky 1914 were probably one and the same species. These authors made the new combination Micromonospora melanosporea (Krainsky) Baldacci and Locci.

Actinomyces melanocyclus is cited in the 7th edition of Bergey's Manual of Determinative Bacteriology (21) as Streptomyces melanocyclus (Merker 1911 [13]) Waksman and Henrici 1948. This appears to be a reasonably interpreted author citation from Krainsky's paper (5), which probably should have cited Actinomyces melanocyclus (Merker 1911) comb. nov. (basonym: Micrococcus melanocyclus Merker). The data given by Krainsky for Actinomyces melanocyclus do not appear adequate for either species recognition or generic placement of this organism. Microscopic data are not adequate for its inclusion in the monosporic actinomycetes, and the colony and aerial mycelium descriptions do not seem adequate for inclusion of this organism with the streptomycetes. No extant culture is known for this organism. Data given by Krasil'nikov (8) for Actinomyces melanocyclus include spiral sporophores and the excretion of a dark-brown substance into the substrate. No reference strain is mentioned, and this information does not appear in either Merker's or Krainsky's descriptions. Waksman (21) attributes antibiotic production to some strains of Streptomyces melanocyclus, but references to these strains are not given.

Owing to the absence of definitive data on Actinomyces melanocyclus, the relationship, if any, between Actinomyces purpureochromogenes Waksman and Curtis 1916 and Actinomyces melanocyclus (Merker) Krainsky 1914 cannot be determined. Agreement with Baldacci and Locci (1) that Actinomyces melanocyclus (Merker 1911) Krainsky 1914 is probably identical with Actinomyces melanosporeus Krainsky 1914 would logically lead to the recognition of Actinomyces melanosporeus as a later subjective synonym of Actinomyces melanocyclus and require making the correct new combination for Micromonospora melanosporea (Krainsky 1914) Baldacci and Locci 1961.

\section{MATERIALS AND METHODS}

Bacterial strains. Micromonospora fusca M-1021 was obtained from Louise F. Potter, Streptomyces purpureochromogenes ATCC 3343 from Erwin F. Lessel, Streptomyces purpeochromogenus (sic) CBS from G. A.
DeVries, and Streptomyces purpureochromogenes IMRU 3343 from Ruth E. Gordon. Strain 68-I was isolated by the author from soil.

Maintenance medium. Cultures were maintained on a medium consisting of $0.5 \%$ yeast extract (Difco), $0.5 \%$ NZ Amine type A (an enzyme digest of casein prepared by Sheffield Chemical Co., Norwich. N. Y.), $1 \%$ glucose (Merck and Co., Rahway, N. J., reagent grade), $2 \%$ soluble starch (Difco), $0.1 \% \mathrm{CaCO}_{3}$ (Merck reagent grade), and $1.5 \%$ agar (Difco) in distilled water. A broth medium was prepared which differed only in the absence of the agar (referred to as $6 \mathrm{~b}$ medium). Incubation of cultures was carried out at room temperature ( 23 to $25 \mathrm{C}$ in humidified glass-door cabinets) unless otherwise stated.

Carbohydrate utilization. Carbohydrates were autoclaved separately to minimize decomposition and were added to the basal medium in a $1 \%$ concentration, except for glycerol, which was added in a $2 \%$ concentration. A basal medium composed of $0.5 \%$ yeast extract, $0.1 \%$ $\mathrm{CaCO}_{3}$, and $1.5 \%$ agar in distilled water was dispensed in 100-ml portions into screw-capped bottles and was sterilized by autoclaving for 15 $\min$ at 15 psi. Test carbohydrates were dispensed dry in 1-g quantities in metal-capped (Morton closure) tubes (25 by $150 \mathrm{~mm}$ ) and were autoclaved for $12 \mathrm{~min}$ at fast exhaust, which was generally satisfactory for sterilizing high-purity carbohydrates. A $10-\mathrm{ml}$ quantity of sterilized, distilled water was added aseptically to the sterilized carbohydrate, and the tube was agitated for $20 \mathrm{~min}$ on a shaker. The yeast extract-agar base was cooled to $60 \mathrm{C}$, and the carbohydrate solutions or suspensions were aseptically added to the agar, mixed, dispensed in $5-\mathrm{ml}$ quantities in metal-capped tubes ( 16 by $150 \mathrm{~mm}$ ), and slanted. Utilization was judged by comparing the amount of colony growth on the test carbohydrate surface to the negative (basal medium only) and the positive (glucose tube) controls after 21 days.

Nitrate reduction. Nitrate reduction was tested for in inorganic and organic broths containing nitrate. The inorganic medium was a sucrose nitrate broth made by leaving out the agar in sucrose nitrate agar (22). The organic nitrate broth consisted of $0.5 \%$ yeast extract, $1.0 \%$ glucose, $0.5 \% \mathrm{KNO}_{3}, 0.1 \% \mathrm{CaCO}_{3}$, and $1,000 \mathrm{ml}$ of distilled water. The broths were dispensed in $10-\mathrm{ml}$ quantities in metal-capped tubes $(25$ by $150 \mathrm{~mm})$. The sterile solutions were inoculated and then incubated on a rotary shaker at $28 \mathrm{C}$. Nitrite was tested for by the procedure outlined in the Manual of Microbiological Methods (18). 
Sodium chloride tolerance. Sodium chloride tolerance was determined in a basal medium containing $1 \%$ yeast extract, $2 \%$ soluble starch, $1.5 \%$ agar, distilled water, and the appropriate concentration of reagent-grade $\mathrm{NaCl}$.

Potato plug acidity tolerance test. The $p \mathrm{H}$ of the autoclaved potatoes used in this investigation varies between 5.8 to 6.1 . The $p \mathrm{H}$ of local varieties of potato should be measured. Potatoes are cut to measure approximately 1 by 1 by $6 \mathrm{~cm}$ and then cut diagonally to produce potato wedges. The wedges are placed at the bottom of metal-capped tubes ( 25 by $150 \mathrm{~mm}$ ). To half of the potato wedges, a small amount of $\mathrm{CaCO}_{3}$ is added, and the wedges are autoclaved. The amount of $\mathrm{CaCO}_{3}$ added should be sufficient to neutralize the weakly acidic potato but not so much as to prevent the organism from reaching the substrate. Aseptically, $10 \mathrm{ml}$ of sterilized agar (1.5\%) is carefully added to the tube containing the sterilized potato plug and then sianted. (The agar prevents the plug from drying out over long incubation periods.) The potato wedge should be inoculated over the entire upper exposed surface.

Milk hydrolysis. Milk hydrolysis is detected on the following medium: (i) yeast extract, $0.5 \%$; glucose, $1.0 \%$; $\mathrm{CaCO}_{3}, 0.2 \%$; agar, $2.0 \%$; and distilled water; (ii) reconstitute skim milk (Difco) as directed on bottle; (iii) autoclave (i) and (ii) separately; milk should not coagulate if autoclaved for $12 \mathrm{~min}$. (iv) While still hot, aseptically mix equal volumes of (i) and (ii) together (in $55 \mathrm{C}$ water bath) and pour into petri plates. A 100 - to $200-\mathrm{ml}$ capacity screwcapped dilution bottle is ideal for mixing.

Observations on spores and sporophores. The study of spore and sporophore development was most often carried out in shaken broth culture. The following broths were made up in $10-\mathrm{ml}$ volumes in metal-capped tubes ( 25 by $150 \mathrm{~mm}$ ) and were inoculated and incubated at $28 \mathrm{C}$ on a rotary shaker. Medium A consisted of: yeast extract $(0.1 \%)$, soluble starch $(0.1 \%)$, glucose $(0.1 \%), \mathrm{CaCO}_{3}(0.1 \%)$, and distilled water. Medium B consisted of: yeast extract $(1.0 \%)$, soluble starch $(2.0 \%)$, and distilled water. Medium $\mathrm{C}$ consisted of: yeast extract $(0.5 \%)$, glucose $(1.0 \%), \mathrm{CaCO}_{3}(0.1 \%)$, and distilled water. Medium D consisted of: yeast extract $(0.1 \%)$, glucose $(1.0 \%), \mathrm{CaCO}_{3}(0.1 \%)$, and distilled water.

The length of incubation of the inoculated broths was dependent upon the rapidity of sporulation. Some cultures sporulate in 48 to $96 \mathrm{hr}$ and then fragment. Other cultures require several weeks to sporulate. Media A through D may also be used as agars (1.5\% agar) for char- acterizing colony development and the color changes often occurring with the development of sporulation.

\section{RESULTS}

The carbohydrate-utilization data are presented in Table 1 . The utilization of glycerol by the dark-diffusible-pigment-producing micromonosporae appears to be unique. Some utilization-pattern variation is apparent among these strains and in a strain (no. 46) reported in an earlier publication (11). The utilization pattern is different from those reported previously (12). Streptomyces purpureochromogenes ATCC 3343 is included for comparison and, as mentioned earlier, is a streptomycete belonging to the species Streptomyces griseus.

Strains IMRU 3343, M-1021, and 68-I (hereafter referred to as the IMRU 3343 group) are very sensitive to concentrations of $\mathrm{NaCl}$ in the test medium. Growth and diffusible-pigment production are reduced at $\mathrm{NaCl}$ concentrations of $1.5 \%$ and do not occur at $3 \%$. By contrast, ATCC 3343 (strain of Streptomyces griseus) grows well at an $\mathrm{NaCl}$ concentration of $7 \%$, which is the average tolerance for streptomycetes (19).

Slow but good growth and diffusiblepigment production occur on potato plugs without $\mathrm{CaCO}_{3}$ (acid potato) for the IMRU 3343 group. Growth appears restricted on the potato plugs to which $\mathrm{CaCO}_{3}$ was added. This is an unusual result not encountered with most of the micromonosporae, which prefer neutral or basic conditions. Both the descriptions by Waksman and Curtis (23; Actinomyces purpureochromogenes) and by Jensen (4; Micromonospora fusca) for growth on potato plugs are remarkably similar and fit the present rate of growth and colony color of IMRU 3343 on this substrate.

Waksman and Curtis (23) stated that "a brown soluble pigment is produced which shows a distinct purple tinge, when viewed by transmitted light." This could be demonstrated for the dark-diffusible-pigment-producing strains in this study if petri dish cultures were held up to natural daylight, but it was not easily demonstrated when viewed against artificial fluorescent lighting. The dark-brown to black agar-diffusible pigment typical of these strains was found to be water-soluble and precipitable upon acidification but was resoluble upon the addition of base; this suggests a melanin-like property but requires chemical confirmation.

On milk agar plates, growth is good for the IMRU 3343 group. The dark, diffusible pig- 
ment does not diffuse readily beyond the periphery of the colonies. Hydrolysis of casein is poor or very slow and restricted to an area usually either under the colony or only a short distance from the periphery of the colony. Most of the micromonosporae previously observed on this substrate are rapidly and strongly proteolytic and clear large zones in the milk or often clear the whole petri dish. In litmus milk tubes, clearing of the milk varied with the strain. IMRU 3343 produced $10 \%$ clearing; 68-I, 20\% clearing; and M-1021, 50\% clearing. It was not determined whether this was brought about by hydrolysis or coagulation. An acid reaction was observed for the three strains. Most proteolytic micromonosporae produce 90 to $100 \%$ clearing in litmus milk within 14 days.

Nitrate reduction appeared variable among the strains of the IMRU 3343 group. Strain 68-I generally appeared positive, whereas IMRU 3343 and M-1021 were usually negative. Jensen (4) reported nitrate reduction as variable; one of the two Micromonospora fusca strains reduced nitrate, the other did not. The IMRU 3343 group grew very slowly on Czapek's sucrose agar ( 30 to 90 days) and produced a brown, diffusible pigment. Growth was rated as fair to poor.

Growth was good at 26 and $37 \mathrm{C}$ but did not occur at $45 \mathrm{C}$ for the IMRU 3343 group.

Microscopic morphology. In broth, colonies of the IMRU 3343 group appear as mycelial networks, often showing a tendency to disintegrate (lyse) into mycelial fragments and chlamydosporic components (Fig. 1-5). Spores may be found singly or in clusters within the mycelial mesh. A predominantly monopodial system of branching occurs in the sporulating hyphae which may often be best observed at the periphery of the colony. An apparent dichotomous branching of the sporulating hyphae may be due to a sporophore in which a terminal spore is first produced and then subtended by one or more short, secondary sporophores which represent a near right-angle branching rather than a simultaneous forking or bifurcation characteristic of a dichotomy. Jensen's illustration of the sporulating hyphae of Micromonospora fusca (Fig. 6) reveals, in the right-hand drawing, opposite branches terminated by spores which are subtended by shortright-angle sporophores and spores. This superficially apparent dichotomy could be termed a pseudodichotomy and appears actually to represent a terminally congested monopodial branching system. A true forking or dichotomy of a sporophore may occur, but it appears to be more by chance than design. The drawings of
Micromonospora globosa by Krasil'nikov (reference 6, Fig. 93) and by Kriss (reference 10, Fig. 3) show the sporophores mostly in a monopodial arrangement; only rarely do they appear as a pseudodichotomy (see reference 9, p. 243). Kriss stated that the strains upon which he based his description of Micromonospora globosa exhibited a ". . monopodially branching system."

\section{DISCUSSION}

IMRU 3343 was designated by Waksman (22) as the type strain for Streptomyces purpureochromogenes (Waksman and Curtis 1916) Waksman and Henrici 1948, and the characters of this strain are in good agreement with those recorded in the original description of this organism by Waksman and Curtis (23). This strain has been deposited in the American Type Culture Collection as ATCC 27007. On the basis of its morphology and cell wall composition (R. Gordon and T. G. Pridham, personal communications), IMRU 3343 is an organism belonging to the genus Micromonospora Ørskov 1923. Furthermore, a high degree of similarity exists between the type strain (IMRU 3343) of Streptomyces purpureochromogenes and Jensen's descriptions $(3,4)$ of Micromonospora fusca, and the name of the latter is here regarded as a subjective synonym of the former. Therefore the following changes in nomenclature are proposed:

Micromonospora purpureochromogenes (Waksman and Curtis 1916) comb. nov.

Objective synonyms: Actinomyces purpeochromogenus (sic) Waksman and Curtis 1916; Streptomyces purpeochromogenus (sic) (Waksman and Curtis 1916) Waksman and Henrici 1948; Streptomyces purpureochromogenes (Waksman and Curtis) Waksman and Henrici 1948 [preferred spelling of specific epithet as given in 7th edition of Bergey's Manual of Determinative Bacteriology, 1957 (21)].

Subjective synonym: Micromonospora fusca Jensen 1932.

In Table 1, a method is given by which carbohydrate-utilization patterns based upon repeated trials over a period of time (i.e., not replicates) may be compared to determine the stability of these patterns. Frequency of response ( $f$ ) refers to the ratio of the number of trials in which positive utilization was observed (numerator) compared to the total number of trials (denominator). The histograms are constructed from the $f$ values. 

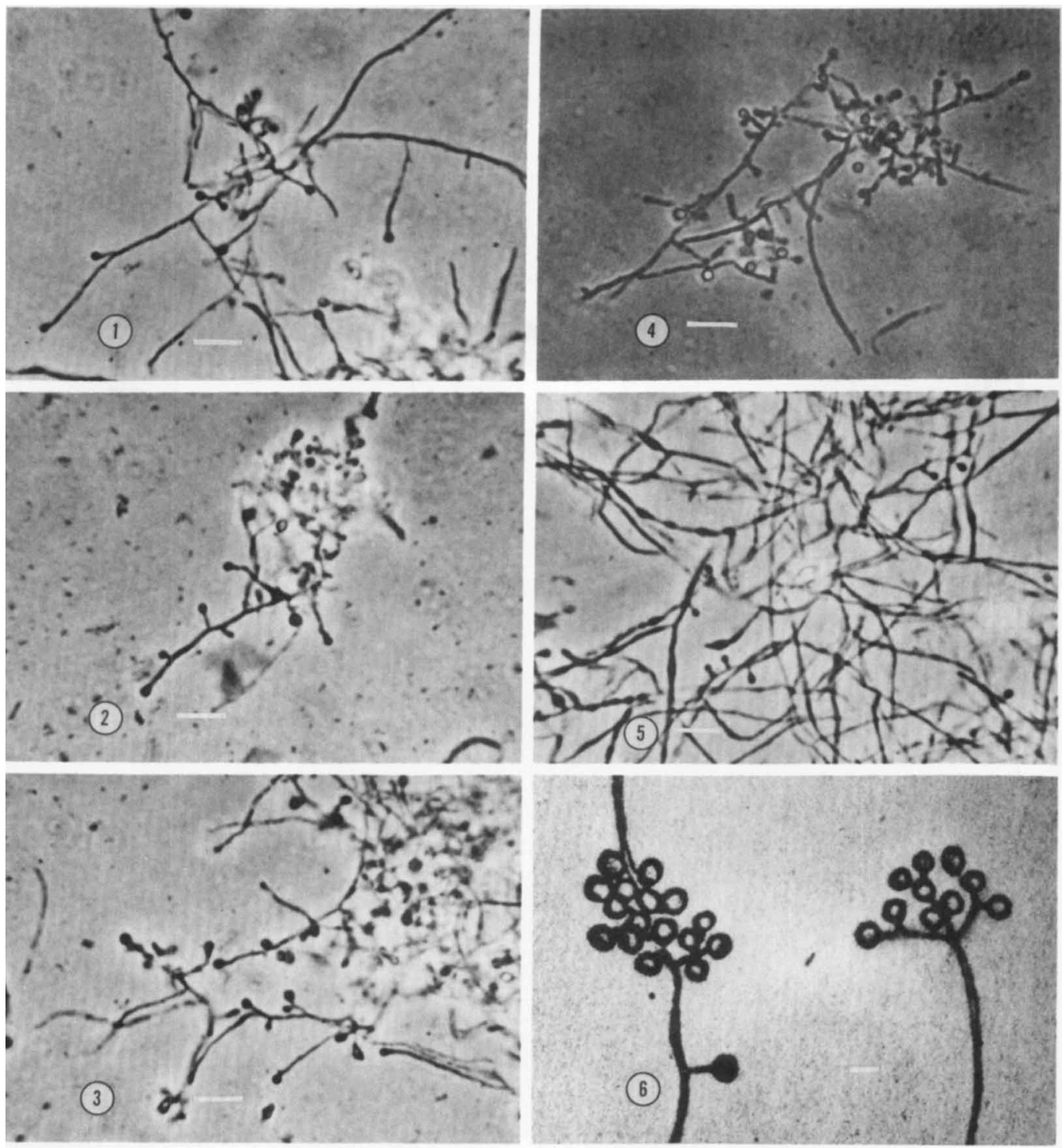

FIG. 1-3. Micromonospora purpureochromogenes (Waksman and Curtis 1916) Luedemann strain IMRU 3343. Fourteen-day broth culture, medium D. Spore and sporophore development as seen at colony periphery. Dense spore clusters develop toward the center of such colonies (Fig. 2-3). Typical monopodial branching. FIG. 4. Soil isolate 68-I (strain identified as Micromonospora fusca). Fourteen-day broth culture, medium A. Characteristics very similar to those illustrated in Fig. 2 and 3. Lysing of mycelium is in progress. Typical monopodial branching. FIG. 5.M-1021 (identified as Micromonospora fusca). Fourteen-day broth culture, medium A. Typical Micromonospora-like spores are evident among many chlamydospore-like elements in the mycelium. FIG. 6. Enlarged photographic reproduction of Jensen's (3) drawing of sporulation in Micromonospora fusca. The clusters of spores at this magnification appear to be derived from a monopodial branching system representing lateral branches upon which are borne terminal spores which are then subtended by subordinate branches or short sporophores (see two opposite lower branches of spore-bearing filament on right-hand side of illustration). The drawing does not indicate a terminal dichotomous branching. In Fig. 1-5, the marker represents $10 \mu \mathrm{m}$; in Fig. 6, $1 \mu \mathrm{m}$. 


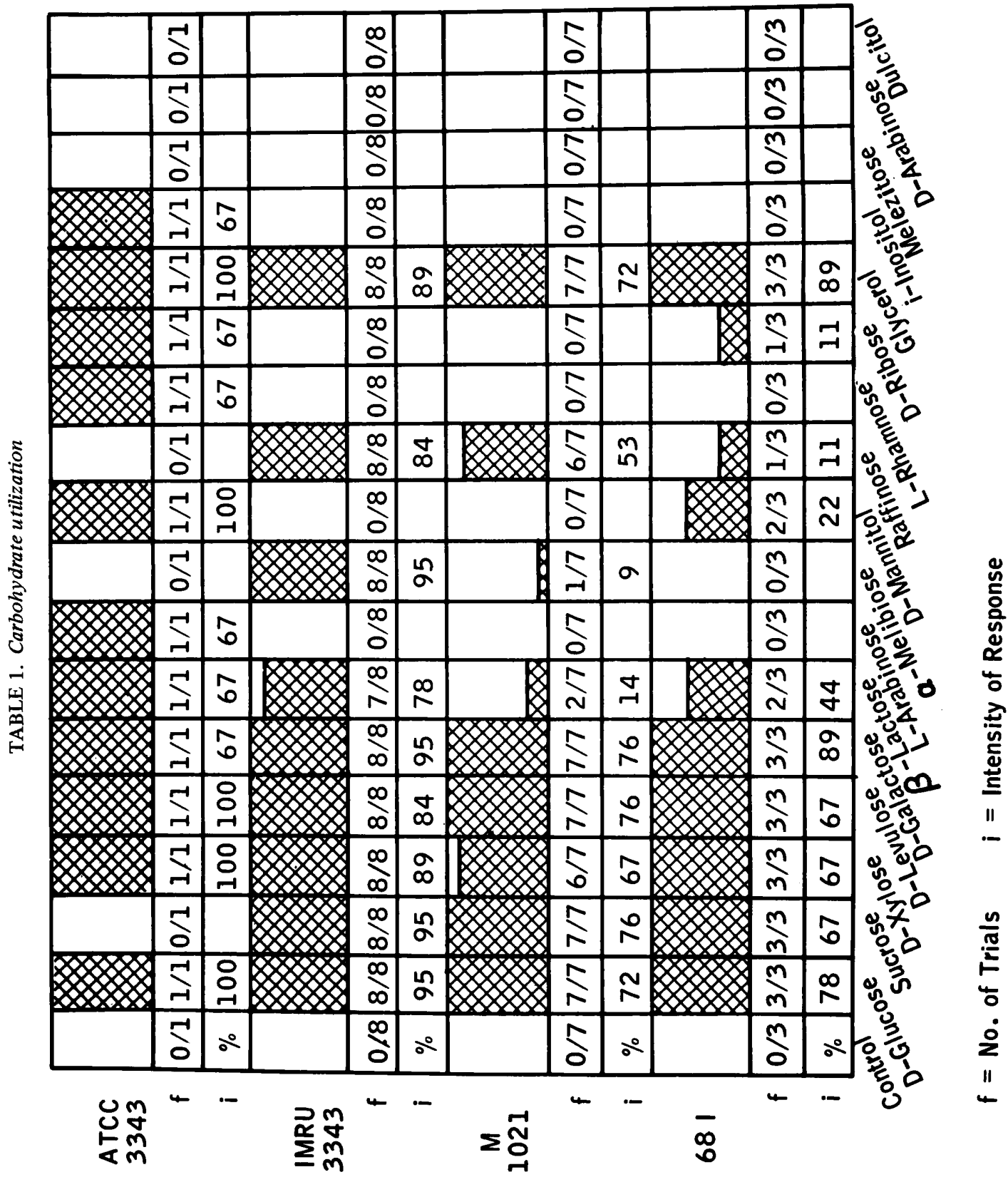

[Frequency of response for any one carbohydrate $(f)=$ number of positive trials/total number of trials.]

Intensity refers to a separate measurement dependent upon the amount of growth observed and is scored as follows for each trial; +++, abundant growth; ++ , moderate growth; + , fair growth, slightly better than the negative control. The total number of plus $(+)$ responses over several trials compared to the maximum number of plus $(+)$ responses possible for that number of trials gives an intensity value (i), which has been converted into a percentage, representing both vigor and reproducibility of growth for a microorganism on a particular carbohydrate substrate. 
$[\mathrm{i}=$ Total observed growth/total possible growth $=$ sum of $t_{s}$ for $\mathrm{N}$ trials $/ 3(+++) \mathrm{N}$ (number of trials).]

\section{LITERATURE CITED}

1. Baldacci, E., and R. Locci. 1961. Osservazioni e ricerche su Micromonospora melanosporea comb. nov. e descrizione di una nuova sottospecie: $M$. melanosporea subsp. corymbica. Ann. Microbiol. Enzimol. 11:19-30.

2. Ettlinger, L., R. Corbaz, and R. Hütter. 1958. Zur Systematik der Actinomyceten. 4. Eine Arteinteilung der Gattung Streptomyces Waksman et Henrici. Arch. Mikrobiol. 31:326-358.

3. Jensen, H. L. 1930. The genus Micromonospora Orskov, a little known group of soil microorganisms. Proc. Linn. Soc. N.S.W. 55:231-249.

4. Jensen, H. L. 1932. Contributions to our knowledge of the Actinomycetales. III. Further observations on the genus Micromonospora. Proc. Linn. Soc. N.S.W. 57:173-180.

5. Krainsky, A. 1914. Die Aktinomyceten und ihren Bedeutung in der Natur. Zentralbl. Bakteriol. Parasitenk. Abt. 2 41:649-688.

6. Krasil'nikov, N. A. 1938. Ray fungi and related organisms-Actinomycetales. Akademii Nauk, SSSR, Moscow.

7. Krasil'nikov, N. A. 1941. Keys to Actinomycetales. Izdatel'stvo Akademii Nauk, SSSR, Moskva-Leningrad (English translation, S. Nemchonok, 1966, U.S. Dept. of Commerce, Clearing House for Federal Scientific and Technical Information, Springfield, Va. 22151).

8. Krasil'nikov, N. A. 1949. Guide to the identification of bacteria and actinomycetes. Academy of Sciences, USSR, Moscow. [English translation of sections pertaining to actinomycetes, J. B. Routien (ed.), Chas. Pfizer and Co., 1957] .

9. Krasil'nikov, N. A., and N. S. Agre. 1965. The brown group of Actinobifida chromogena n. sp. Mikrobiologiya 34:284-291 (English translation).

10. Kriss, A. E. 1939. The micromonospore-an actinomycete-like organism (Micromonospora globosa n. sp.). Mikrobiologiya 8:178-185.

11. Luedemann, G. M. 1969. Micromonospora taxonomy, p. 101-133. In D. Perlman (ed.), Advances in applied microbiology, vol. 11. Academic Press Inc., New York.
12. Luedemann, G. M. 1971. Species concepts and criteria in the genus Micromonospora. Trans. N.Y. Acad. Sci. 33:207-218.

13. Merker, E. 1911. Parasitische Bakterien auf Blättern von Elodea. Zentralbl. Bakteriol. Parasitenk. Abt. 2 31:578-590.

14. Orskov, J. 1923. Investigation into the morphology of the ray fungi. Levin and Munksgaard, Copenhagen.

15. Pridham, T. G. 1964. Taxonomic studies of Streptomyces griseus (Krainsky) Waksman and Henrici: a species comprising many subspecies. Antimicrob. Ag. Chemother. 1963, p. 104-115.

16. Pridham, T. G., and A. J. Lyons, Jr. 1969. Progress in clarification of the taxonomic and nomenclatural status of some problem actinomycetes, p. 183-221. In C. J. Corum (ed.), Developments in industrial microbiology, vol. 10. Garamond/Pridemark Press, Baltimore.

17. Pridham, T. G., A. J. Lyons, and H. L. Seckinger. 1965. Comparison of some dried holotype and neotype specimens of streptomycetes with their living counterparts. Int. Bull. Bacteriol. Nomencl. Taxon. 15:191-237.

18. Society of American Bacteriologists. 1957. Manual of microbiological methods. McGraw-Hill Book Co., Inc., New York.

19. Tresner, H. D., J. A. Hayes, and E. J. Backus. 1968. Differential tolerance of streptomycetes to sodium chloride as a taxonomic aid. Appl. Microbiol. 16:1134-1136.

20. Waksman, S. A. 1919. Cultural studies of species of Actinomyces. Soil Sci. 8:71-215.

21. Waksman, S. A. 1957. Family III. Streptomy. cetaceae Waksman and Henrici, 1943. p. 744825. In R. S. Breed, E. G. D. Murray, and N. R. Smith (ed.), Bergey's manual of determinative bacteriology, 7th ed. The Williams \& Wilkins Co., Baltimore.

22. Waksman, S. A. 1961. The Actinomycetes, vol. II. Classification, identification and description of genera and species. The Williams \& Wilkins Co., Baltimore.

23. Waksman, S. A., and R. E. Curtis. 1916. The Actinomyces of the soil. Soil Sci. 1:99-134.

24. Waksman, S. A., and A. T. Henrici. 1948. Family III. Streptomycetaceae Waksman and Henrici, 1943, p. 929-980. In R. S. Breed, E. G. D. Murray, and A. Parker Hitchens (ed.), Bergey's manual of determinative bacteriology, 6 th ed. The Williams \& Wilkins Co., Baltimore. 